\title{
Kendini Sabote Etmenin Yakın Kişilerarası İlişkiler Açısından Ele Alınması
}

DOI: $10.26466 /$ opus.893279

\author{
Ayșegül Sayan Karahan* \\ * Dr, Türkiye Adalet Akademisi, Ankara/ Türkiye \\ E-Posta: pskaysegulsayan@hotmail.com \\ ORCID: 0000-0002-5580-0617
}

\begin{abstract}
Öz
$\mathrm{Bu}$ literatür incelemesi, kendini sabote etme kavramının yakın kişiler arası ilişkiler açısından ele alınması hakkında bilgileri sunmaktadır. Kendini sabote etme kavramı; akademik başarı ve performans gibi alanlarda çalışılmış olsa da yakın kişiler arası ilişkiler alanında sınırlı olarak ele alındığı ve bu alanda bir boşluk olduğu görülmüştür. Bireylerin olası bir başarısızlık sonucu öngördükleri durumlarda bu sonuca yol açacak davranış ve stratejileri kullanmaları anlamına gelen kendini sabote etme kavramının işlevleri ve özellikleri hakkında kuramsal açıklamalar gözden geçirilmiştir. Ulaşılabilen ve yakın kişiler arası ilişkiler ile ilişkili araştırmalar özetlenmiştir. Yakın kişiler arası ilişkilerde kendini sabote etmenin nedenleri, süreçleri ve etkileri vurgulanarak korku, kendine ve ilişkiye güven ve iletişim becerileri açısından tartışılmıştır. Bireylerin yakın kişiler arası ilişkilerde kendini sabote etmesine yönelik olarak bu gereksinime neden olan etkenlere ve bu stratejileri kullanmanin sonuçlarına ilişkin önerilerde bulunulmuştur. Yakın kişiler arası ilişkilerde kendini sabote etme kavramının ele alınmasına ilişkin daha ileri nitel ve nicel araştırmalarla ilgili öneriler sunulmuştur.
\end{abstract}

Anahtar Kelimeler: Kendini Sabote Etme, Yakın İlişkiler,Kendini Engelleme. 


\title{
Consideration of Self-Sabotage Regarding Close Relationships
}

\begin{abstract}
This literature review provides information about self-handicapping in terms of close interpersonal relationships. Although self-handicapping has been studied in fields such as academic achievement and performance, it has been observed that there is limited research in the field of close interpersonal relations and there is a gap in this area. The theoretical explanations regarding the functions and characteristics of self-handicapping, which means that individuals utilize some behaviors and strategies that will lead to a failure in situations they anticipate as a result, have been reviewed, The literature which are accessible and related to close interpersonal relationships are summarized. The reasons, processes and effects of self-handicapping in close interpersonal relationships are emphasized and discussed in terms of fear, self-reliance, reliance to relationship and communication skills. Suggestions about the factors that cause this need and the consequences of using these strategies, were made. Suggestions for further qualitative and quantitative research were presented.
\end{abstract}

Keywords: Self-Sabotage, Close Relationships, Self-Blocking. 


\section{Giriş}

Baumesister ve Leary (1995) insanların kalıcı, olumlu ve anlamlı kişiler arası ilişkiler geliştirmek ve sürdürmek için yaygın bir güdüye sahip olduklarını ileri sürmüştür. Toplumsal bağlar geliştirme gereksinimi güçlü olduğu gibi bu bağların yokluğu ya da kaybı da etkilidir. Yakın kişiler arası ilişkiler kendiliğinden oluşmamakta, çekimden doğan duygu ve davranışların bir sonucu olarak, elde etme evresi sonucunda geliştirilmektedir. Bireyler için diğerleri ile bağlantılı olmak yeterli değildir, buna ek olarak bu bağlantıyı sürdürme beklentisi de bulunmaktadır. İlişkiyi sürdürme hem devam etmeyi hem de kararlı olmayı ve ilişkinin iyi işler durumda olmasını kapsamaktadır. Yakın kişiler arası ilişkilerin sürdürülmesi ilişkisel çabayı ve ilişkiyi sürdürme stratejilerini gerektirmektedir. İletişim ilişkilerin temelini oluşturmakta ve ilişki kuralları geliştirilmektedir. İlişkinin niteliği ya da kalitesine bağlı olarak ilişki doyumu farklılık göstermektedir. Kişisel katılım, duygusal bağlanma ve sürekli etkileşim içeren yakın ilişkiler bireyler için hem mutluluk hem de kaygı kaynağı olabilmektedir. İlişkinin tarafları arasında özgül davranışlar, davranış normları, kişiler eğilimler, farklılıkları ele alma gibi nedenlerle yıkıcı ya da yapıcı çatışmalar yaşanabilmekte, bu çatışmaların sıklığı ve nasıl ele alındığı farklılık gösterebilmektedir. Yakın ilişkilerde gücün kullanımına bağlı olarak farklı türlerde şiddet içeren deneyimler yaşanabilmektedir. Yakın kişiler arası ilişkiler çeşitli nedenlerle bozulabilmekte, çözülebilmekte ve sona erebilmektedir (Dönmez, 2009)

Yakın kişiler arası ilişkilerin çekim, elde etme, sürdürme, durum ve çatışmaları ele alma, bozulma ve sona erme aşamalarında ilişkinin taraflarının nasıl hissettiklerinin, düşündüklerinin ve davrandıklarının ilişkinin hem istikrarı hem de kalitesi açısından etkili olabileceği görülmektedir. Bu bağlamda ilişkinin taraflarının bekledikleri olumsuz sonuçları elde etme olasılı̆̆ını artıracak şekilde davranma eğilimi şeklinde tanımlanabilecek olan kendini sabote etmeyi yakın kişiler arası ilişkilerde sergilemeleri ilişki istikrarı ve kalitesiyle ilişkili olarak düşünülebilir. Kendini sabote etme, bireylerin kapasite ya da potansiyellerine uyumlu sonuçlar elde etmelerini ve dolayısıyla motivasyon ve doyum düzeylerini olumsuz etkileyen bir eğilim olarak tarif 
edilmektedir. Dolayısıyla akademik ve mesleki açıdan literatürde ele alınmış olan kendini sabote etmenin kişiler arası ilişkiler açısısından da ele alınıp alınmadığı merak edilmiştir. Kendini sabote etmenin yakın kişiler arası ilişkilerle ilişkili olarak ele alındığı bu derleme çalışmasının öncelikle bu ilişkiye dikkat çekmesi beklenmektedir.

Kendini sabote etmenin bireyin kendisini engelleme etkisine ek olarak, yakın kişilerarası ilişkiler bireylerin yaşamında merkezi ve önemli bir yere sahiptir (Dönmez, 2009). Yakın kişilerarası ilişkiler bireylerin yaşamlarını anlamlandırmalarında ve yakınlık, sevgi, bağlantıda olma gibi temel sosyal ve duygusal gereksinimlerini karşılamada belirleyici olmaktadır. Bu bağlamda, bireylerin yaşamlarını anlamlandırma ve yakınlık, sevgi, bağlantıda olma gibi temel sosyal ve duygusal gereksinimlerini karşılama alanı olan yakın kişilerarası ilişkilerinde elde edebilecekleri sonuçları daha olumsuz hale getirebilme eğilimlerinin anlaşılmasının ve üzerinde çalışılmasının önemli olduğu düşünülmüştür.

Kendini sabote etmenin ve yakın kişiler arası ilişkilerin önemi ve etkilerine rağmen, kendini sabote etmenin yakın kişiler arası ilişkiler çalışmaları kapsamında ele alındığı yurt dışı ve yurt içi sınırlı sayıda çalışmaya rastlanmış ve bu alanda bir boşluk olduğu görülmüştür. Kendini sabote etmenin yakın kişiler arası ilişkiler alanı kapsamında da ele alınabilecek önemli bir kavram olabileceği düşünülmüştür. Yakın kişiler arası ilişkiler içindeki bireylerin kendini sabote etmeye ilişkin özellikleri ile bu özelliklerin bireyler, bireylerin oluşturduğu ilişkiler, ilişkilerinde çözmeleri gereken problem durumları ve güçlü yönleri açısından nasıl ele alınabileceğine ilişkin bir bakış açısı geliştirilmeye çalışılmıştır.

Sağlıklı yakın kişilerarası ilişkiler geliştirmek yaşam doyumu açısından önemli bir alanı oluşturmaktadır. Yakın kişilerarası ilişkilerde kendini sabote etme sağlıklı yakın kişilerarası ilişkileri hem kurabilme hem de sürdürebilme açısından bireyleri etkileyebilecek, böylelikle yaşam doyumuna yansıyabilecek önemli bir alan olarak ele alınabilmektedir. Romantik kendini sabote etme hem bireysel, hem yakın kişilerarası ilişki içinde olunan diğer bireyleri de ilgilendirdiğinden ilişkisel, hem de yakın kişilerarası ilişkilerin evliliğe dönüşebilmesi dolayısıyla aile birliğinin kurulması ya da sürdürülmesi açısından toplumsal etkilere sahip olabilmektedir. Kendini sabote etme kavramının yakın kişiler arası ilişkiler alanında ele alınmasının bu kavramın bireyler ve aralarındaki 
ilişki dinamikleri üzerindeki etkileri ve sonuçlarının daha iyi anlaşılabilmesi açısından katkı sağlayabileceği düşünülmüştür.

Kendini sabote etme kısa vadede bireyin kendini koruma amacına hizmet ediyor olsa da uzun vadede kronik hale gelerek kişilik özelliğine dönüşebilmekte ve böylelikle yaygın olumsuz etkilere yol açabilmektedir (Abacı ve Akın, 2011; Hendrix ve Hirt, 2009; Martin, Richardson, Bergen, Roeger ve Allison, 2005). Bir diğer deyişle, birey farklı yakın kişilerarası ilişkilerde benzer bir kendini sabote etme eğilimi sergilediğinde ve bu nedenle tekrarlayan biçimde olumsuz sonuçlarla karşılaştığında yakın kişilerarası ilişkilere yönelik inancını kaybedebilmekte ya da kendisiyle ilgili bir sorun olduğunu düşünebilmektedir. Bireyler yakın kişilerarası ilişkiler alanında yaşadıkları bu tür deneyimler nedeniyle psikolojik danışmaya başvurabilmektedir. Kendini sabote etmenin yakın kişilerarası ilişkiler alanındaki yansımalarına yönelik geliştirilecek bir anlayışın bu alandaki terapotik çalışma ve uygulamaların etkililiğini artırmaya yönelik hizmet edebileceği düşünülmüştür.

Romantik kendini sabote etme konusunda klinik uygulamalara ek olarak akademik çalışmalara da gereksinim olduğu literatür taraması ile görülmektedir. Daha ileri araştırmalar ile yakın kişilerarası ilişkilerde kendini sabote etmeye ilişkin bir ölçme aracının geliştirilmesi veya uyarlanması, bir modelin geliştirilmesi ve test edilmesi, bireysel veya grupla iyileştirici ve geliştirici uygulamaların etkililiğinin sağlanması gereksinimi açısından bu derlemenin yol gösterici olabileceği düşünülmüştür.

\section{Kuramsal Çerçeve}

Literatür incelendiğinde kendini sabote etme kavramının kendini sabotaj, kendini engelleme gibi farklı şekillerde ifadelerine rastlanmaktadır. Literatürde kendini sabote etme kavramının çeşitli şekillerde tanımlandığ1 görülmektedir (Hirt, McCrea ve Boris, 2003; Leary ve Shepperd, 1986; Sarıçalı, 2014; Smith, Snyder ve Perkins, 1983; Tannenbaum, 2007; Tice, 1991). Yapılan tanımların ortak yönlerine bakıldığında kendini sabote etme; başarısız olma, yetersiz olma, saygınlığı ya da öz saygıyı kaybetme sonucunun beklendiği durumlarda bu olası sonuç için 
kendini haklı gösterecek dışsal yüklemeler, makul dışsal nedenler, bahaneler ya da engeller oluşturma stratejisi olarak ifade edilebilmektedir.

Kendini sabotaj teriminin ortaya çımasına Festinger'in (1957) bilişsel uyumsuzluk kuramı ve Kelley'in (1973) yükleme teorisi gibi kuramsal açıklamalar zemin hazırlamıştır. Bilişsel uyumsuzluk kuramı (aktaran, Sertel, 2019), tutumlar ya da davranış-tutum arasında bir çelişki algilanması durumunda bireylerin bu uyumsuzluğu gidermeye ve uyum durumunu sağlamaya çalıştığını ifade etmektedir. Bu bağlamda ele alındığında birey, olumsuz sonuçlanma olasılığının daha fazla olduğunu düşündüğü durumlarda, bu bilişsel uyumsuzluğun üstesinden kendini engelleme stratejileri ile gelebilmektedir. Bir diğer deyişle, başarısızlık sonucunun ortaya çıkmasına yol açacak davranışları ortaya koymaktadır. Yükleme teorisine (aktaran, Albayrak, 2019) göre ise bireylerin nasıl bir performans sergileyeceklerini kavramsallaştırma eğilimlerinde olumlu sonuçları iç ve olumsuz sonuçları diş etkenlere bağlama ve kendilerini başarılı göstermeye yönelik bir çaba içinde oldukları ileri sürülmektedir (Berglas ve Jones, 1978). Bireyler başarısızlığı dışsal etkenlere bağlayabilmek için kendi kendilerine engeller oluşturma ve böylece, başarısız olması durumunda üstleneceği bireysel sorumluluğu azaltma, yetersizliğini teşhis etmekten kaçınma ve başarı durumunda duyulacak tatmini ise artırma yoluna gitmektedirler. (Jones ve Berglas, 1978; Leary ve Shepperd, 1986).

Kendini sabote etme, bireyin erken gelişim dönemlerinden itibaren kendisiyle ve başarıyla ilişkili olumsuz düşünme biçimleriyle ilişkilidir (Kearns, Forbes, Gardiner ve Marshall, 2008; Stewart ve De Leorge Walker, 2014; Warner ve Moore, 2004). Bireylerin performanslarını önemsedikleri, başarısızlık olasılığı olan, başarı olasılıklarından şüphe ettikleri, başarısızlığın geçerli ve haklı görülebilecek başka bir sebebi olmadığ 1 durumlarda ve benliklerini koruma amacına yönelik olarak kendilerini sabote etme davranışları sergiledikleri belirtilmektedir (Albayrak, 2019; Berglas ve Jones, 1978; Coşar, 2012; McCrea ve Hirt, 2001; Rhodewalt ve Vohs, 2005; Zuckerman, Kieffer ve Knee, 1998).

Kendini sabote eden bireyler, olası başarısızlık durumunda benliklerini korumak amacıyla, hazırlanmak yerine performanslarını düşürebilecek elverişsiz şartları kendileri oldukça dikkatli biçimde oluşturmaktadırlar (Akın, Abacı ve Akın, 2011). Bu durum pygmalion 
etkisi ya da olumsuz kendini gerçekleştiren kehanet kavramları ile de açıklanabilmektedir. Böylece, birey elde edeceği olumsuz sonucu, stratejiler kullanarak önceden hazırlamaktadır (Hendrix ve Hirt, 2009).

Bireyin benliğini koruyabilmek ve başarısızlıkları ile yüzleşmekten kaçınmak için kullandığı bu strateji zamanla bireyin süreklilik gösteren bir davranış biçimi ya da kişilik özelliği haline gelebilmekte, problemlerin gerçekçi şekilde değerlendirilmesini engellemekte, bireyin başarısızlık olasılığını yükseltmekte ve böylece bireye zarar vermektedir (Abacı ve Akın, 2011; Hendrix ve Hirt, 2009; Martin, Richardson, Bergen, Roeger ve Allison, 2005).

Kendini sabote eden bireyler çoğunlukla başarısızlık öncesinde çok çaba sarf etmektense daha az performans göstermeyi seçmektedir. Başarılı sonuç elde etmeyi engelleyecek durumları performanstan önce veya performans esnasında oluşturmaktadır (Baumgardner ve Levy, 1988). Literatür incelendiğinde; davranışsal kendini sabotaj (behavioral self-handicapping) ve sözlü/öz bildirimli kendini sabotaj (claimed/selfreported self-handicapping) olmak üzere iki çeşit kendini sabote etme stratejisinden söz edildiği görülmektedir. Sözlü kendini sabotaj, performans öncesi çeşitli psikolojik belirtilerin sözel olarak ifade edilmesi ve mazeretler ileri sürülmesi gibi örtük ve pasif eylemleri içermektedir. Davranışsal kendini sabotaj ise erteleme, fırsatları değerlendirmeme, yeterli çaba harcamama, farklı konularla uğraşma, kadercilik, fiziksel belirtiler gösterme, kapasitesinin üstünde yüklenme, alkol-madde kullanımı gibi performansı etkileyebilecek daha aktif ve açık eylemlerde bulunmaktadır (Higgins, 1990; Hendrix ve Hirt, 2009; Kearns ve diğerleri, 2008; Leary ve Shepperd, 1986; Tucker, Sobel ve Vuchinich, 1981).

\section{Literatür Taraması}

Kendini sabotaj eğilimi literatürde sıklıkla akademik başarı ile ilişkilendirilmekte, öğrencilerden oluşan örneklemler üzerinde çok sayıda araştırma gerçekleştirilmektedir (Chemers, Hu ve Garcia, 2001; Hirt, 1991; Lane, Lane ve Kyprianou, 2004; Lent, Brown ve Larkin, 1986; Marsh ve O'Mara, 2008; Multon, Brown ve Lent, 1991; Urdan, 2004; Zuckerman ve diğerleri, 1998) 
Kendini sabotaj davranışı ile hata yapmaktan, başarısız olmaktan korkma (Elliot ve Church, 2003; Elliot ve Thrash, 2004), kayg1 (Abacı ve Akın, 2011), endişe (Sahranç, 2011), kaygı duyarlılığı (Kalyon, Dadand1 ve Yazıc1, 2016), sosyal anksiyete (Schlenker ve Leary, 1982, Coudevylle, Martin-Ginis ve Famose, 2011), mükemmeliyetçilik (Kearns ve diğerleri, 2008; Sertel, 2019) arasında anlamlı ve pozitif ilişkiler bulunduğu bildirilmektedir.

Düşük benlik saygısına sahip kişilerin kendilerini daha çok engelledikleri (Elmas ve Aşçı, 2017; Martin ve Brawley, 2002; McCrea ve Hirt, 2001; Thomas ve Gadbois, 2007), düşük öz yeterlilik algısının da kendini sabotaj eğilimini arttırdığı yönünde araştırma sonuçları mevcuttur (Stewart ve GeorgeWalker, 2014). Kendini yeterli bulmayan, öz saygısı ve öz-yeterlik algısı düşük olan kişilerin kendilerini daha fazla engellediği bildirilmektedir (Üzbe ve Bacanl1, 2015). Ayrıca dışsal yönelim kendini engellemeyle ilişkili bulunmaktadır (Akça, 2012; Stewart ve Walker, 2014).

Kendini engelleyen bireylerin daha olumsuz hissettikleri ve yaşam tatminlerinin daha az olduğu bildirilmektedir (Christopher, Lasane, Troisi ve Park, 2007; Zuckerman ve Tsai, 2005). Bu açıdan, kendini engelleyenlerin daha düşük sağlık ve iyilik halinde olduğu bildirilmektedir (Maata, Statin ve Nurmi, 2002).

Hangi özelliklere sahip bireylerin kendini sabotaj stratejilerini daha çok kullandığını belirlemeye yönelik yürütülen araştırma bulgularına göre; güçlüklerle mücadele konusunda gücüne ve kaynaklarına güven duyan (Berglas ve Jones, 1978), sosyal desteği olan, sosyal olarak aktif olan ve etkili iletişim kurabilen (Büyükgöze ve Gün, 2015) bireylerin bu tür stratejilere daha az gereksinim duyduğu bildirilmiştir.

\section{Tartışma ve Sonuç}

Kendini sabote etme ile ilgili kuramsal açıklamalar ve literatür incelendiğinde; olası olumsuz sonuç beklentisi durumunda, söz konusu sonuç için haklı ve makul açıklamaları sağlayacak şekilde sözlü ya da davranışsal olarak kendini engelleme olarak tanımlanabileceği, başlangıçta kendini koruma amacına hizmet ediyor gözükse de bireylerin hem karşılaşacakları sonuçlar hem de kendileriyle ilgili algı ve 
değerlendirmeleri açısından olumsuz sonuçlar doğurabileceği, bu tür eğilimleri daha çok sergileyenlerin daha yüksek düzeyde kaygı ve daha düşük düzeyde benlik saygısı ile öz yeterlik algısına sahip olduğu, sosyal becerilerin bu tür bir eğilime gereksinimi azalttığı görülmektedir.

Kendini sabote etme eğilimi akademik, mesleki ya da performans durumlarında görülebileceği gibi bireylerin hayatında merkezi ve önemli bir yere sahip olan yakın kişilerarası ilişkilerde de ortaya çıkabilmektedir. Kendini koruma amacına hizmet ettiği ve kaygıyla ilişkili olduğu bildirilen bu eğilimin, bireyler için incinebilirliğin yüksek olduğu yakın kişilerarası ilişkilere nasıl yansıdığına ilişkin literatürün sınırlı olduğu görülmüştür.

Yakın kişilerarası ilişkilerde kendini sabote etme ya da bir diğer deyişle romantik kendini sabotaj; ilişkide başarıyı engelleme veya çaba göstermeyerek ilişkide başarısızlığı haklı göstermek için kendine zarar veren davranış örüntüleri olarak tanımlanmaktadır. Neden bazı bireylerin romantik ilişkilerde kendini sabote eden bir döngüde takılıp kaldığına ilişkin sınırlı bulgular bulunmaktadır. Peel, McBrain, Caltabiano ve Buck (2019) tarafından yürütülen nitel bir araştırmada ilişki danışmanlığı alanında çalışan psikologlar ve başarısız ilişkiler yaşamış katılımclardan romantik sabotaj davranışlarını tarif etmeleri istenmiştir. Katılımcılar tarafından tanımlanan kendini sabote etme davranışları repertuarı 12 ana temada ele alınmıştır. Bu ana temalar; partnere saldırı (örn; eleştiri ve iletişim becerileri eksikliği), partneri takip (örn; yapışkanlık), partnerin geri çekilmesi (örn; engelleme), savunmacılık, aşağılama, benlik saygısı, kontrol etme eğilimi, ilişki becerileri, güven güçlükleri, yıkıcılık eğilimi (örn; aşırı içme), işlere karşı tutum ve ilişki inançları olarak bildirilmiştir.

İlişkileri sabote etmeye yol açan olası motivasyonlar ele alınmıştır (Epstein ve Baucom, 2002; Gottman, 1993; Johnson, 2004). Katılımcılar romantik bir ilişkiyi sürdürememenin beş temel nedenini korku, benlik saygısı güçlüğü ve olumsuz benlik kavramı, kırılmış güven, yüksek beklentiler ve ilişki becerileri eksikliği olarak ifade etmişlerdir. Korku, ilişkileri sabote etmede en yaygın güdü olarak belirtilmiştir. Katılımcılar tarafından ifade edilen dört temel korku; kırılma korkusu, reddedilme korkusu, terk edilme korkusu ve bağlanma korkusudur. 
Bireyler ilişkilerini yıkıcı olma niyeti barındırmaksızın tek bir nedenle sabote etmektedir. Aslında temelde kendini korumayı amaçlayan davranış ve tutumlar, bireylerin ilişki başarısızlığı ve kendi güvensiz inançları arasında sıkışıp kalmasıyla kendini sabote edici hale gelmektedir. Kendilerini nasıl korudukları sorulduğunda katılımcıların bildirdiği altı yıkıcı ilişki örüntüsü; ilişkiden geri çekilme, savunmacılık, numara yapmak, ilişki takibi, partnere saldırı, kaçma-kovalama dinamiğidir. Sağlıklı uzun süreli ilişkiler için beş büyük ilişki beklentisi ise; güven, iletişim, bağlılık, güvenlik ve kabul olarak tanımlanmıştır. (Peel ve Caltabiano, 2020).

Bireyin yakın kişilerarası ilişkilerinde kendini sabote etmesini önlemeye yönelik olarak bireyin benliğini korumak için kendini sabote etme davranışına ihtiyaç duymamasını sağlamanın ve bireyin ilişkiyi sabote ettiğine dair içgörüye sahip olmasını sağlamanın uygun yardım yaklaşımları olduğu belirtilmektedir. Bir diğer ifadeyle bireylerin bu davranış biçimlerinin, bu davranışa duydukları gereksinimin kaynaklarının, davranışın sonunda elde ettiklerine nasıl yansıdığının ve etkilerinin farkına varmalarının sağlanması gereklidir. Buna ek olarak benliğin güçlendirilmesine yönelik olarak bireysel ya da grupla çalışılabilmektedir (Greenberg ve Johnson, 1998; Greenberg, Warwar ve Malcom, 2010; Gottman ve Silver, 2015; Üzar Özçetin ve Hiçdurmaz, 2016).

İlişki becerileri bireylerin nasıl ilişkide olabileceklerini öğrenmelerinde ve kendileri ile diğerleri hakkında temel inançlarını geliştirmelerinde, ilişkide olmanın kaçınılmaz stresörleri ile başa çımada ve birlikte kalabilmek için dayanıklılık geliştirmede yardımcı olabilmektedir. Kendini sabote etme döngüsünü kırmanın temel bir süreci de kırılmanın ilişkinin doğal bir kısmı olduğunun kabulüdür (Peel ve Caltabiano, 2020).

Hangi özelliklere sahip olan bireylerin, nasıl ilişkilerde, hangi durumlarda ve hangi nedenlerle yakın kişilerarası ilişkilerde kendini sabote etme stratejilerine başvurdukları hakkında nitel araştırmalara gereksinim olduğu görülmektedir. Bu tür nitel araştırmaların bulgularının ışı̆̆ı altında ve nicel araştırma bulgularıyla da desteklenerek yakın kişilerarası ilişkilerde kendini sabote etmeyi açıklamaya yönelik bir modelin geliştirilmesi mümkün olabilecektir. Ayrıca yakın kişilerarası ilişkilerde kendini sabote etmeye yönelik bir ölçme aracının Peel ve diğerleri (2019) 
tarafından geliştirilme ve yayımlanma aşamasında olduğu bildirilmiştir. Romantik kendini sabote etmeye yönelik ölçme aracının uyarlanması ve kültürel olarak test edilmesi, ya da bir ölçme aracı geliştirilmesine yönelik çalışmalara gereksinim olduğu görülmektedir. Bu tür araştırma bulgularından hareketle yakın kişilerarası ilişkilerde kendini sabote etmeyi önlemeye yönelik bireysel ya da grupla psiko-eğitsel program ya da terapotik uygulamaların geliştirilmesi ve etkililiğinin test edilmesine yönelik araştırmalar fayda sağlayacaktır.

Romantik kendini sabotajda korku, güven, iletişim ve ilişki becerileri kavramlarının çalışılması fayda sağlayacaktır. Yakın kişilerarası ilişkiler döngüsel süreçler içermektedir ve partnerler birbirlerinin davranışlarından etkilenmekte ve birbirlerini etkilemektedir. Bir diğer ifadeyle ilişkinin taraflarının davranışlarının sorumluluğunu almaları beklenmektedir. Buna ek olarak sağlıklı yakın kişilerarası ilişkiler problem ya da anlaşmazlık yaşanmayan ilişkiler olmaktan çok problem ya da anlaşmazlık çözme becerisi olan partnerlerin ilişkisi olarak tanımlanmaktadır. Bir diğer ifadeyle yakın kişilerarası ilişkilerde problem ya da anlaşmazlık yaşamanın normal ve doğal olduğu, bunların üstesinden gelebilmek için destek kaynaklarının mevcut olduğu bilgisi bireylere fayda sağlayacaktır. Ayrıca bilişsel yöntemlerle bireylerin yakın kişilerarası ilişkilerde korktukları durumların başlarına gelmesi halinde en kötü ne olabileceği ve bunun kendileri, hayatları ve gelecekleri için ne anlama gelebileceği sorgulatılabilir. Ek olarak, bireylerin kendini koruma ihtiyaçlarının farkında olup bu ihtiyacı sabote edici olmayan ve sağlıklı bir yolda ifade edebilmeleri, kendini sabote eden davranışlar sergilediklerinde ise bu davranışların olumsuz etkilerinin farkında olup kendilerine ve partnerlerine bu farkındalığ 1 ifade edebilmeleri ve durdurabilmeleri konularında desteklenmeleri fayda sağlayacaktır.

Sağlıklı yakın kişiler arası ilişkiler kurabilmek ve sürdürebilmek yetişkin yaşam görevleri arasında önemli görülmektedir. Yakın kişiler arası ilişkilerde romantik kendini sabote etme bireylerin yaşam doyumunda olumsuz etkilere yol açabilecektir. Dolayısıyla bireylerin yakın kişiler arası ilişkilerde kendini sabote etme davranışlarına başvurma gereği duymaksızın yaşamalarına yönelik iyileştirici ve geliştirici bireysel ve grupla psikolojik danışma uygulamalarının geliştirilip uygulanması fayda sağlayabilecektir. Bu tür uygulamaların geliştirilip uygu- 
lanabilmesi amaciyla öncelikle romantik kendini sabote etmenin anlaşılması gerekli olmaktadır. Kendini sabote etmenin romantik ilişkilerde nasıl yaşandığının anlaşılması, bu alanda bir ölçek ve model gelişimine de katkı sağlayacaktır. Hangi özelliklere sahip bireylerin, hangi tür kişiler arası yakın ilişkilerde, hangi durumlarda kendini sabote etme davranışı sergilediğinin belirlenmesine yönelik nitel ve nicel araştırmaların yürütülmesine gereksinim olduğu görülmektedir. Romantik kendini sabote etme kavramına ilişkin araştırmaların bulgularının ışığında müdahalelerin etkililiğine yönelik deneysel çalışmaların yürütülmesinin de bu alandaki boşluğun giderilmesine katk1 sağlayacağ1 düşünülmektedir. 


\title{
EXTENDED ABSTRACT
}

\section{Consideration of Self-Sabotage Regarding Close Relationships}

\author{
Ayşegül Sayan Karahan
}

Adalet Akademisi

Baumesister and Leary (1995) argued that people have a pervasive drive to develop and maintain lasting, positive, and meaningful interpersonal relationships. It is not enough for individuals to be connected with others, in addition, there is an expectation to maintain this connection. Maintaining close interpersonal relationships requires relational effort and relationship maintenance strategies (Dönmez, 2009).

It is seen that how the parties of the relationship feel, think and behave in the stages of attraction, acquisition, maintenance, handling of situations and conflicts, deterioration and termination of close interpersonal relationships can be effective in terms of both the stability and quality of the relationship. In this context, self-handicapping, which can be defined as the tendency of the parties to behave in a way that increases the possibility of obtaining the negative results they expect, can be thought of as related to the stability and quality of the relationship.

Self-sabotage has been studied in fields such as academic achievement and performance. This concept is considered to be a tendency that negatively effects individuals' achievement of results that are compatible with their capacities or potentials and thus their motivation and satisfaction levels. It is thought that it is important to understand and explore this tendency regarding the field of close relationships, as a domain of making sense of their lives and meeting basic social and emotional needs such as closeness, love, and connection. Self-handicapping in close interpersonal relationships can be considered as an important field that can effect individuals regarding both to establish and maintain healthy close interpersonal relationships and thus reflect on life satisfaction. Despite the importance and effects of self-sabotage and close interpersonal rela- 
tionships, there have been a limited number of studies where selfhandicapping has been discussed within the scope of close interpersonal relationships, and it has been observed that there is a gap in this field. Considering self-sabotage within the scope of close interpersonal relationships would serve to further research regarding development of a scale, a model and effective therapeutic implications in this field.

Based on the common aspects of the definitions, self-sabotage can be defined as a strategy of creating reasonable external causes, excuses, obstacles or external attributes to justify the possible outcome, in cases where failure, inadequacy, loss of dignity or self-esteem is expected. Theoretical explanations such as Festinger's (1957) cognitive dissonance theory and Kelley's (1973) attribution theory led to the emergence of the term of self-sabotage.

Self-handicapping individuals carefully create unfavorable conditions themselves that may reduce their performance instead of being prepared, in order to protect themselves in case of possible failure (Akın, Abacı and Akın, 2011). This situation can be explained by the pygmalion effect or negative self-fulfilling prophecy concepts (Hendrix \& Hirt, 2009). This strategy used by the individual to protect his/herself and avoid confronting his/her failures can become a continuous behavior or personality trait of the individual over time, prevents the realistic evaluation of problems, increases the possibility of failure of the individual and thus harms the individual (Abacı and Akın 2011; Hendrix and Hirt 2009; Martin, Richardson., Bergen, Roeger and Allison, 2005).

It is seen that there are two types of self-handicapping strategies in the literature; behavioral self-handicapping and verbal / self-reported self-handicapping. Self-handicapping tendency is frequently associated with academic achievement, anxiety, self-concept, social aspects, wellbeing, mental and physical health in the literature.

Romantic self-sabotage is defined as self-harming behavioral patterns to justify failure in the relationship by preventing success in the relationship or not making an effort. Self-handicapping behaviors described in a qualitative study conducted by Peel, McBrain, Caltabiano, and Buck (2019) were; attack on the partner (e.g. criticism and lack of communication skills), pursuit partner (e.g. stickiness), withdrawal (e.g. blocking), defensiveness, humiliation, self-esteem, tendency to control, relationship 
skills, trust difficulties, destructiveness (e.g. binge drinking), attitudes towards issues, and relationship beliefs. Five main reasons for not being able to maintain a romantic relationship were expressed as fear, difficulty in self-esteem and negative self-concept, broken trust, high expectations, and lack of relationship skills. Fear has been cited as the most common motive for sabotaging relationships. The four basic fears were; fear of being hurt, fear of rejection, fear of abandonment and fear of attachment.

In order to prevent the individual from self-handicapping in close interpersonal relationships, it is stated that strenghtening self to ensure that the individual does not need self-handicapping behavior in order to protect his/herself and having an insight that $\mathrm{s} /$ he sabotages the relationship are appropriate approaches. In addition, relationship skills can help individuals learn how to be in a relationship, develop basic beliefs about themselves and others, cope with the inevitable stressors of being in a relationship, and develop resilience to stay together. A fundamental process of breaking the cycle of self-handicapping is the acceptance that breaking is a natural part of the relationship (Peel and Caltabiano, 2020).

\section{Kaynakça / References}

Abacı, R. ve Akın, A. (2011). Kendini Sabotaj insanoğlunun sınırlı doğasının bir sonucu. Ankara: Pegem Akademi Yayıncilı.

Akça, F. (2012). An investigation into the self-handicapping behaviors of undergraduates in terms of academic procrastination, the locus of control and academic success. Journal of Education and Learning, 1(2), 288-297. doi:10.5539/jel.v1n2p288

Akın, A., Abacı, R. ve Akın, Ü. (2011). Self-handicapping: A conceptual analysis. International Online Journal of Educational Sciences, 3(3), 11551168.

Albayrak, H. (2019). Lise öğrencilerinin kendini sabote etme eğilimi ile psikolojik iyi olma, depresyon ve öz yeterlik arasindaki ilişkinin incelenmesi. Yayımlanmamış Yüksek Lisans Tezi. Trabzon Üniversitesi, Lİsansüstü Eğitim Enstitüsü, Rehberlik ve Psikolojik Danışmanlık Bilim Dalı, Trabzon. 
Baumeister, R. F and Leary, M.R. (1995). The need to belong: Desire for interpersonal attachments as a fundamental human motivation. Psychological Bulletin, 117, 497-529.

Baumgardner, A. H. and Levy, P. E. (1988). Role of self-esteem in perceptions of ability and effort: Illogic or insight? Personality and Social Psychology Bulletin, 14(3), 429-438. https://doi.org/10.1177/0146167288143001

Berglas, S. and Jones, E. E. (1978). Drug choice as a self-handicapping strategy in response to noncontingent success. Journal of Personality and Social Psychology, 36(4), 405-417. https://doi.org/10.1037/00223514.36.4.405

Büyükgöze, H. ve Gün, F. (2015). Araştırma görevlilerinin kendini sabotaj eğilimlerinin incelenmesi. Hitit Üniversitesi Sosyal Bilimler Enstitüsü Dergisi, 8(2), 689-704. http://dx.doi.org/10.17218/husbed.11352

Chemers, M. M., Hu, L. and Garcia, B. F. (2001). Academic self-efficacy and first-year college student performance and adjustment. Journal of Educational Psychology, 93(1), 55-64. https://doi.org/10.1037/00220663.93.1.55

Christopher, A.N., Lasane, T.P., Troisi, J.D. and Park, L.E. (2007) Materialism defensive, and assertive self-presentational tactics, and life satisfaction. Journal of Social Clinical Psychology, 26, 1145-1162. https://doi.org/10.1521/jscp.2007.26.10.1145

Coşar, S. (2012). Çalışanların tükenmişlik düzeyleri ile kendini engelleme düzeyleri arasındaki ilişkinin incelenmesi. Yayımlanmamış Yüksek Lisans Tezi. Maltepe Üniversitesi, Sosyal Bilimler Enstitüsü, Psikoloji Ana Bilim Dalı, İstanbul.

Coudevylle, G., Martin Ginis, K. and Famose, J.-P. (2008). Determinants of selfhandicapping strategies in sport and their effects on athletic performance. Social Behavior and Personality, 36, 391-398. DOI: 10.2224/sbp.2008.36.3.391

Dönmez, A.(2009). Yakın ilişkiler psikolojisi. Ankara: Nobel Yayın

Elliot, A. J. and Church, M. A. (2003). A motivational analysis of defensive pessimism and self-handicapping. Journal of Personality, 71(3), 369396. https://doi.org/10.1111/1467-6494.7103005

Elliot, A. J. and Thrash, T. M. (2004). The intergenerational transmission of fear of failure. Personality and Social Psychology Bulletin, 30(8), 957971. https://doi.org/10.1177/0146167203262024 
Elmas, A. G. ve Aş̧̧ı, F. H. (2017). Sporcularda kendini sabotaj: Benlik saygısı, başarı hedefleri ve başarısızlık korkusunun rolü. Türkiye Klinikleri Journal of Sports Sciences, 9(3), 108-117. Doi: 10.5336/sportsci.2017-55210

Epstein, N. B. and Baucom, D. H. (2002). Enhanced cognitive-behavioral therapy for couples: A contextual approach. Washington, DC: American Psychological Association.

Gottman, J. M. (1993). What predicts divorce? The Relationship between marital processes and marital outcomes. New Jersey: Psychology Press.

Gottman, J. M. and Silver, N. (2015). The seven principles for making marriage work. New York: Three Rivers Press.

Greenberg, L., Warwar, S. and Malcolm, W. (2010). Emotion-focused couples therapy and the facilitation of forgiveness. Journal of Marital and Family Therapy, 36(1), 28-42. DOI: 10.1111/j.1752-0606.2009.00185.x

Greenberg, L. S. and Johnson, S. M. (1998). Emotionally focused therapy for couples. New York: Guilford Press.

Hendrix, K. S. and Hirt, E. R. (2009). Stressed out over possible failure: The role of regulatory fit on claimed self-handicapping. Journal of Experimental Social Psychology, 45, 51-59. https://doi.org/10.1016/j.jesp.2008.08.016

Higgins, R.L. (1990). Self-handicapping: Historical roots and contemporary branches. In R.L. Higgins, C.R. Snyder, S. Berglas (Eds.), Selfhandicapping: The paradox that isn't (p.1-35). New York: Plenum Press.

Hirt, E. R., Deppe, R. K. and Gordon, L. J. (1991). Self-reported versus behavioral selfhandicapping: Empirical evidence for a theoretical distinction. Journal of Personality and Social Psychology, 61, 981-991. https://doi.org/10.1037/0022-3514.61.6.981

Hirt, E. R., McCrea, S. M. and Boris, H. I. (2003). I know you selfhandicapped last exam: Gender differences in reactions to selfhandicapping. Journal of Personality and Social Psychology, 84(1), 177193. https://doi.org/10.1037/0022-3514.84.1.177

Johnson, S. M. (2004). The practice of emotionally focused couple therapy: Creating connection. (2nd ed.). New York: Brunner-Routledge.

Jones, E. E. and Berglas, S. (1978). Control of attributions about the self through selfhandicapping strategies: The appeal of alcohol and the role of underachievement. Personality and Social Psychology Bulletin, 4(2), 200-206. https://doi.org/10.1177/014616727800400205 
Kalyon, A., Dadandı, İ. ve Yazıcı, H. (2016). Kendini sabote etme eğilimi ile narsistik kişilik özellikleri. Düşünen Adam, 29(3), 237-246. DOI: 10.5350/DAJPN2016290305

Kearns, H., Forbes, A., Gardiner, M. ve Marshall, K. (2008). When a high distinction isn't good enough: A review of perfectionism and selfhandicapping. Australian Educational Researcher, 35(3), 21-36.

Lane, J., Lane, A. M. ve Kyprianou, A. (2004). Self-efficacy, self-esteem and their impact on academic performance. Social Behavior and Personality, 32(3), 247-256. DOI: https://doi.org/10.2224/sbp.2004.32.3.247

Leary, M. R. and Shepperd, J. A. (1986). Behavioral self-handicaps versus self-reported handicaps: A conceptual note. Journal of Personality and Psychology, 51(6), 1265-1268. https://doi.org/10.1037/00223514.51.6.1265

Lent, R. W., Brown, S. D. and Larkin, K. C. (1986). Self-efficacy in the prediction of academic performance and perceived career options. Journal of Counseling Psychology, 33(3), 265-269. https://doi.org/10.1037/00220167.33.3.265

Maata, S., Stattin, H. and Nurmi, J.E. (2002). Achievement strategies at school: Types and correlates. Journal of Adolesence, 25, 31-46. DOI: 10.1006/jado.2001.0447

Marsh, H. W. and O'Mara, A. (2008). Reciprocal effects between academic self-concept, self-esteem, achievement, and attainment over seven adolescent years: Unidimensional and multidimensional perspectives of self-concept. Personality and Social Psychology Bulletin, 34(4), 542-552. DOI: 10.1177/0146167207312313

Martin, G., Richardson, A. S., Bergen, H. A., Roeger, L. and Allison, S. (2005). Perceived academic performance, self-esteem and locus of control as indicators of need for assessment of adolescent suicide risk: Implications for teachers. Journal of Adolescence, 28, 75-87. DOI: 10.1016/j.adolescence.2004.04.005

Martin, K. A. and Brawley, L. R. (2002). Self-handicapping in physical achievement settings: The contributions of self-esteem and selfefficacy. Self and Identity, 1(4), 337-351. https://doi.org/10.1080/15298860290106814

McCrea, S.M. ve Hirt, E.R. (2001). The Role of Ability judgments in selfhandicapping. Personality and Social Psychology Bulletin, 27, 13781389. https://doi.org/10.1177/01461672012710013 
Multon, D.K., Brown, D.S. and Lent, W.R. (1991). Relation of self efficacy beliefs to academic outcomes: A meta analytic investigation. Journal of Counseling Psychology, 38, 30-38. doi:10.1037/0022-0167.38.1.30

Peel,R. ve Caltabiano, N. (2020). Why do we sabotage love? a thematic analysis of lived experiences of relationship breakdown and maintenance. Journal of Couple \& Relationship Therapy, 20(2), 99-131. DOI: 10.1080/15332691.2020.1795039

Peel, R., McBrain, K., Caltabiano, N. and Buck, B. (2019). The romantic selfsaboteur: How do people sabotage love? Conference: International Convention on Psychological Science.

Rhodewalt, F. and Vohs, K. (2005). Defensive strategies, motivation and the self: A self regulatory process view. In A. J. Elliot ve C. S. Dweck (Eds.). Handbook of Competence and Motivation (p.548- 565). New York: Guilford Press.

Sahranç, Ü. (2011). An investigation of the relationships between selfhandicapping and depression, anxiety, and stress. International Online Journal of Educational Sciences, 3(2), 526-540.

Sarıçalı, M. (2014). Psikolojik danışman adaylarının kendini engelleme algılarının özgünlük düzeyleri ve aldikları süpervizyon açısından incelenmesi. Yayımlanmamış Yüksek Lisans Tezi. Anadolu Üniversitesi, Eğitim Bilimleri Enstitüsü, Rehberlik ve Psikolojik Danışmanlık Bilim Dalı, Eskişehir.

Schlenker, B.R. and Laary, M.R. (1982). Social anxiety and self-presentation: A conceptualization and model. Psychology Bulletin, 92, 641-669. DOI: 10.1037/0033-2909.92.3.641

Sertel, G. (2019). Yönetici ve öğretmenlerin kendini sabotaj düzeyleri ile okullardaki örgütsel iklim algıları arasındaki ilişkinin incelenmesi. Yayımlanmamış Yüksek Lisans Tezi. Pamukkale Üniversitesi, Eğitim Bilimleri Enstitüsü, Eğitim Bilimleri AnaBilim Dalı, Denizli.

Smith, T. W. Snyder, C.R. and Perkins, S. C. (1983). The self-serving function of hypochondriacal complaints: Physical symptoms as selfhandicapping strategies. Journal of Personality and Social Psychology, 40(4), 787-797. DOI: 10.1037//0022-3514.44.4.787

Stewart, M. A. and De George-Walker, L. (2014). Self-handicapping, perfectionism, locus of control and self-efficacy: A path model. Personality and Individual Differences, 66, 160-164. https://doi.org/10.1016/j.paid.2014.03.038 
Tannenbaum, R. E. (2007). Goal orientation, work avoidance goals, and selfhandicapping in community college students. Unpublished Doctoral Dissertation. Capella University, Minneapolis.

Thomas, C. R. and Gadbois, S. A. (2007). Academic self-handicapping: The role of selfconcept clarity and students' learning strategies. British Journal of Psychology, 77, 101-119. https://doi.org/10.1348/000709905X79644

Tice, D. M. and Baumeister, R. F. (1990). Self-esteem, self-handicapping, and selfpresentation: The strategy of inadequate practice. Journal of Personality, 58(2), 443-464. https://doi.org/10.1111/j.14676494.1990.tb00237.x

Tucker, J.A., Sobell, M.B. and Vuchinich, R.E. (1981) Alcohol consumption as a self-handicapping strategy. Journal of Abnormal Psychology, 90, 220-230. https://doi.org/10.1037/0021-843X.90.3.220

Urdan, T. (2004). Predictors of academic self-handicapping and achievement: Examining achievement goals, classrom goal structures and culture. Journal of Educational Psychology. 96(2), 251-264. https://doi.org/10.1037/0022-0663.96.2.251

Üzar-Özçetin, Y.S. ve Hiçdurmaz, D. (2016). Kendini sabote etme ve ruh sağlığı üzerine etkisi. Psikiyatride Güncel Yaklaşımlar- Current Approaches in Psychiatry. 8(2), 145-154. doi:10.18863/pgy.13806

Üzbe, N. ve Bacanlı, H. (2015). Başarı hedef yönelimi, benlik saygısı ve akademik başarının kendini engellemeyi yordamadaki rolü. Türk Eğitim Bilimleri Dergisi, 13(1), 33-50.

Warner, S. and Moore, S. (2004). Excuses, excuses: Self-handicapping in an Australian adolescent sample. Journal of Youth and Adolesence, 33, 271-281. DOI: 10.1023/B:JOYO.0000032636.35826.71

Zuckerman, M., Kieffer, S. C. and Knee, C. R. (1998). Consequences of selfhandicapping: Effects on coping, academic performance and adjustment. Journal of Personality and Social Psychology, 74(6), 1619-1628. https://doi.org/10.1037/0022-3514.74.6.1619

Zuckerman, M. and Tsai, F. F. (2005). Costs of self-handicapping. Journal of Personality, 73(2), 411-442. $\quad$ https://doi.org/10.1111/j.1467$\underline{6494.2005 .00314 . x}$ 


\section{Kaynakça Bilgisi / Citation Information}

Sayan Karahan, A. (2021). Kendini sabote etmenin yakın kişilerarası ilişkiler açısından ele alınması. OPUS-Uluslararası Toplum Araştırmalarn Dergisi, 18(42), 5876-5896. DOI: 10.26466/opus. 893279. 